\title{
Berberine-targeted miR-21 chemosensitizes oral carcinomas stem cells
}

\author{
Che-Yi Lin ${ }^{1}$, Pei-Ling Hsieh ${ }^{2, *}$, Yi-Wen Liao ${ }^{3, *}$, Chih-Yu Peng ${ }^{3}$, Ming-Yi Lu ${ }^{3}$, Ching- \\ Hsuan Yang ${ }^{2}$, Cheng-Chia Yu ${ }^{2,3,4}$ and Chia-Ming Liu' ${ }^{3,4}$ \\ ${ }^{1}$ Department of Oral and Maxillofacial Surgery, Chi Mei Hospital, Tainan, Taiwan \\ ${ }^{2}$ Institute of Oral Sciences, Chung Shan Medical University, Taichung, Taiwan \\ ${ }^{3}$ School of Dentistry, Chung Shan Medical University, Taichung, Taiwan \\ ${ }^{4}$ Department of Dentistry, Chung Shan Medical University, Taichung, Taiwan \\ *These authors have contributed equally to this work \\ Correspondence to: Cheng-Chia Yu, email: ccyu@csmu.edu.tw \\ Chia-Ming Liu, email: y337@csmu.edu.tw
}

Keywords: oral squamous cell carcinomas, miR-21, berberine

Received: June 16, $2017 \quad$ Accepted: August 04, $2017 \quad$ Published: September 08, 2017

Copyright: Lin et al. This is an open-access article distributed under the terms of the Creative Commons Attribution License 3.0 (CC BY 3.0), which permits unrestricted use, distribution, and reproduction in any medium, provided the original author and source are credited.

\section{ABSTRACT}

Cancer recurrence and chemoresistance are two major obstacles to the treatment of oral squamous cell carcinomas (OSCC). And cancer stem cells (CSCs) have been found to possess tumor initiating, self-renewal and metastasis abilities, resulting in the relapse and chemoresistance of OSCC. In the present study, we investigated the anti-CSCs effect of berberine, a phenanthrene alkaloid isolated from the Berberis genus. Our results demonstrated that berberine dose dependently downregulated the oncogenicity in vitro, including ALDH1 activity, self-renewal property, and colony formation and invasion abilities as well as potentiated chemosensitivity of OSCCCSCs. In addition, tumor growth in mice was attenuated after oral gavage treatment of berberine. We showed that the expression of miR-21 was suppressed following administration of berberine in OSCC-CSCs. And inhibition of endogenous miR-21 reduced the characteristics of CSCs, including self-renewal, migration, invasion capabilities and ALDH1 activity. Taken together, we demonstrated the anti-CSC effect of berberine in oral cancer and its potential to serve as adjuvant to traditional chemotherapy to improve treatment effect.

\section{INTRODUCTION}

Oral squamous cell carcinoma (OSCC) represents one of the most common cancers with increased annual incidence [1] and has a high propensity for treatment failure. Resistance to chemo/radiotherapy and recurrence are major causes of mortality in patients with OSCC [2], and there is still a significant number of patients suffer from recurrent cancer after chemotherapy [3]. A small subset of cells, often termed cancer stem cells (CSCs), have been considered as key contributors to drug resistance, tumor relapse and metastasis in OSCC [4]. Hence, agents that eliminate and sensitize the chemoresistant CSCs are extremely crucial to enhance the current treatment effectively.

Berberine is a phenanthrene alkaloid isolated from the roots and bark of plants from the Berberis genus (Berberidaceae family). It has traditionally been used in Oriental medicine and has various biological activities, including anti-microbial [5, 6], anti-inflammatory [7] and antioxidant $[8,9]$ properties. Recent studies have focused on its anti-tumor effects, including anti-metastasis, apoptosis and autophagy induction and epithelial-tomesenchymal transition (EMT) suppression in a wide range of tumor cell types [10-18]. And a number of reports have demonstrated that it induces apoptosis in 
oral cancer cells $[19,20]$. Moreover, it has been shown to diminish CSCs and down-regulate stem cell-associated genes in the pancreatic cancer cell lines [21]. In addition, it was reported to sensitize ovarian cancer cell to cisplatin [22]. Hence, its anti-tumor effect on OSCC-CSCs is worth investigating.

MicroRNAs (miRNAs) are small noncoding RNAs regulating the gene expression at the post-transcriptional level and have been found to be involved in various biological processes [23-25]. In particular, miR-21 has been indicated as one of the most upregulated miRNAs in OSCC [26] and shown to confer resistance to chemotherapy, such as 5-fluorouracil (5-FU) and cisplatin, in hepatocellular carcinoma [27], neuroblastoma [28], colorectal [29], and gastric cancers [30]. Furthermore, it has been shown that berberine suppresses multiple myeloma cell growth by down-regulating miR-21 expression [31]. Accordingly, it is also imperative to elucidate whether berberine and miR-21 are associated with sensitizing the chemoresistant CSCs and eliciting anti-OSCC activity.

In this study, we evaluated the effect of berberine on cell viability, ALDH1 activity, self-renewal, colony formation, invasion abilities in vitro and tumorigenecity in vivo. Additionally, we found that administration of berberine enhanced the tumor sensitization to chemotherapy. Besides, our results demonstrated that administration of berberine decreased the expression of miR-21 in a dose-dependent manner. And inhibition of miR-21 suppressed the features of CSCs, including selfrenewal, migration, invasion capacities and the expression of CSC marker. These data indicate that miR-21 may play a pivotal role in the anti-CSCs property of berberine. In conclusion, we demonstrated the tumor suppressive and chemosensitizing effect of berberine in OSCC-CSCs via regulation of $\mathrm{miR}-21$.

\section{RESULTS}

\section{The cytotoxic effect of berberine on OSCC cancer stem cells (OSCC-CSCs)}

MTT assay was used to determine the cell viability of two OSCC-CSCs (SAS and OECM-1) and normal human gingival epithelioid cell line (SG) after treatment with increasing concentrations of berberine. As shown in Figure 1A, berberine markedly suppressed the cell survival of two OSCC-CSCs without causing toxic damage to normal SG cells. The cytotoxicity data indicated a dose response relationship with respect to berberine and OSCCCSCs viability.

\section{ALDH1 enzymatic activity in OSCC-CSCs was repressed by berberine}

Aldehyde dehydrogenase (ALDH1) enzymatic activity has been shown to be a highly selective marker for CSCs in HNSCC [32]. And it has been suggested that elevated ALDH1 level correlated with local recurrence of OSCC and there were more ALDH1 expressing cells existed in cisplatin-surviving cells [33]. In this study, flow cytometry analysis showed that ALDH1 activity was gradually attenuated in both OSCC-CSCs along with the increase in berberine concentration (Figure 1B), indicating that berberine may be able to suppress the characteristics of OSCC-CSCs.

\section{Reduced self-renewal and oncogenicity abilities in OSCC-CSCs by berberine}

One of the CSCs hallmarks is self-renewal capacity and sphere reformation over serial passages is gold standard method to evaluate this property [34]. Our data showed that self-renewal ability in both OSCC-CSCs was inhibited dose-dependently following administration of berberine (Figure 2). Also, CSCs are known to be equipped with the tumor initiating property and metastatic behavior, both of which are essential for orchestrating field cancerization and tumor recurrence [35]. The result of colony formation assay showed that anchorageindependent growth capability was hindered by the increase in berberine (Figure 3A). To assess the metastatic potential, we treated cells with various concentration of berberine followed by examination of invasion ability using transwell. We observed a dose-dependent effect of berberine on the invasion capacities of OSCC-CSCs (Figure 3B). Altogether, these results clearly demonstrated that berberine exerted a pronounced anti-CSC effect.

\section{Enhanced chemosensitivity in OSCC-CSCs by berberine}

The chemoresistant CSCs has been implicated in the cancer recurrence following conventional therapy [36], hence it is crucial to evaluate whether berberine possess the potential to enhance the efficacy of chemotherapy. As expected, drug-resistance was more prominent in OSCC-CSCs in comparison with parental OSCC cells (Figure 4). Nonetheless, the sensitivity of OSCC-CSCs to both 5-FU and cisplatin was dramatically improved in conjunction with berberine (Figure 4). Collectively, these findings showed that berberine may serve as an adjunct to traditional chemotherapeutic agents.

\section{Administration of berberine exerts a suppressive effect on tumor growth in vivo}

After examining the anti-CSCs effect of berberine in vitro, we investigated its influence on tumorigenicity in xenotransplantation model. Immunocompromised mice bearing OSCC-CSCs xenografts were assigned to receive oral administration of berberine or vehicle followed by tumor volume assessment. The bioluminescent signal in photons per second from the IVIS Spectrum imager 
A
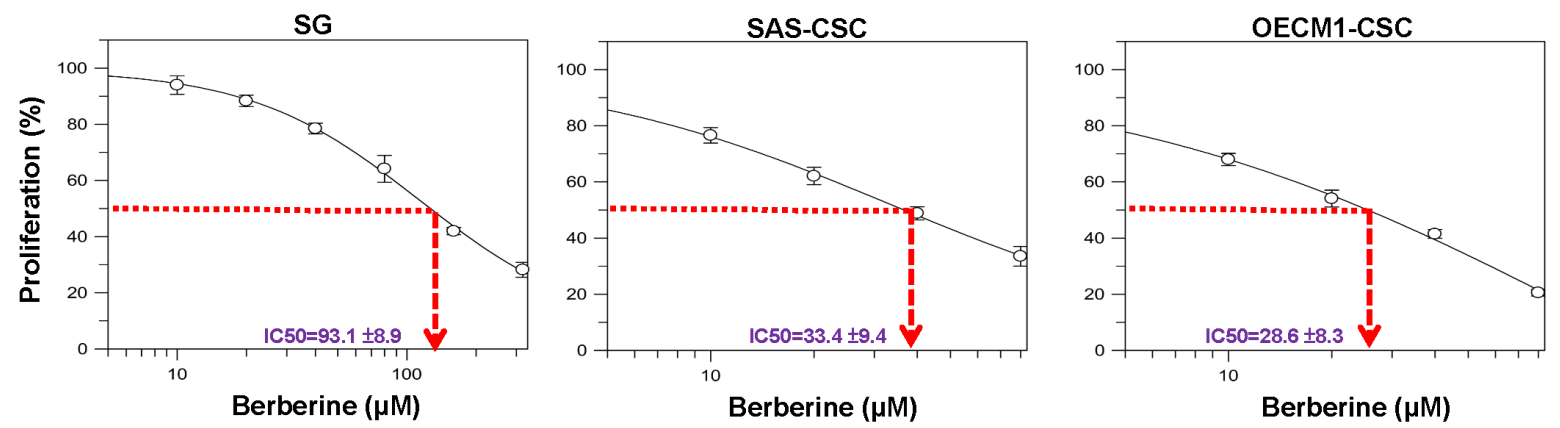

$\mathrm{B}$
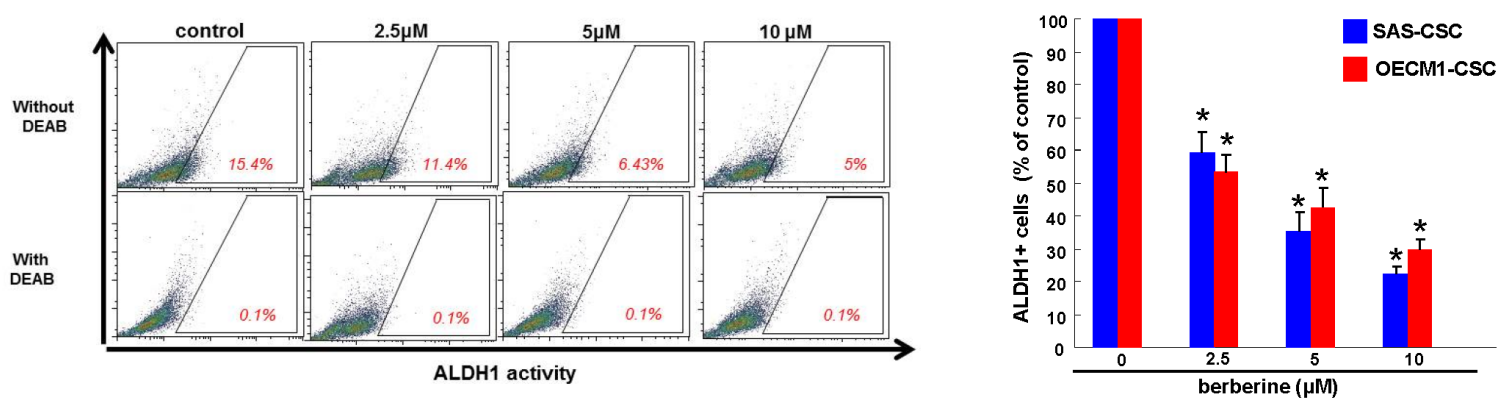

Figure 1: Cell viability and ALDH1 activity of OSCC-CSCs after berberine treatment. (A) Cytotoxic effect was determined by MTT assay. Berberine markedly inhibited the cell survival of OSCC-CSCs in a dose-dependent manner without causing damage to normal cells; (B) ALDH1 enzymatic activity was gradually eliminated in OSCC-CSCs as the concentration of berberine increased. Values were expressed as mean $\pm \mathrm{SD} .{ }^{*} p<.05$ compared to control.
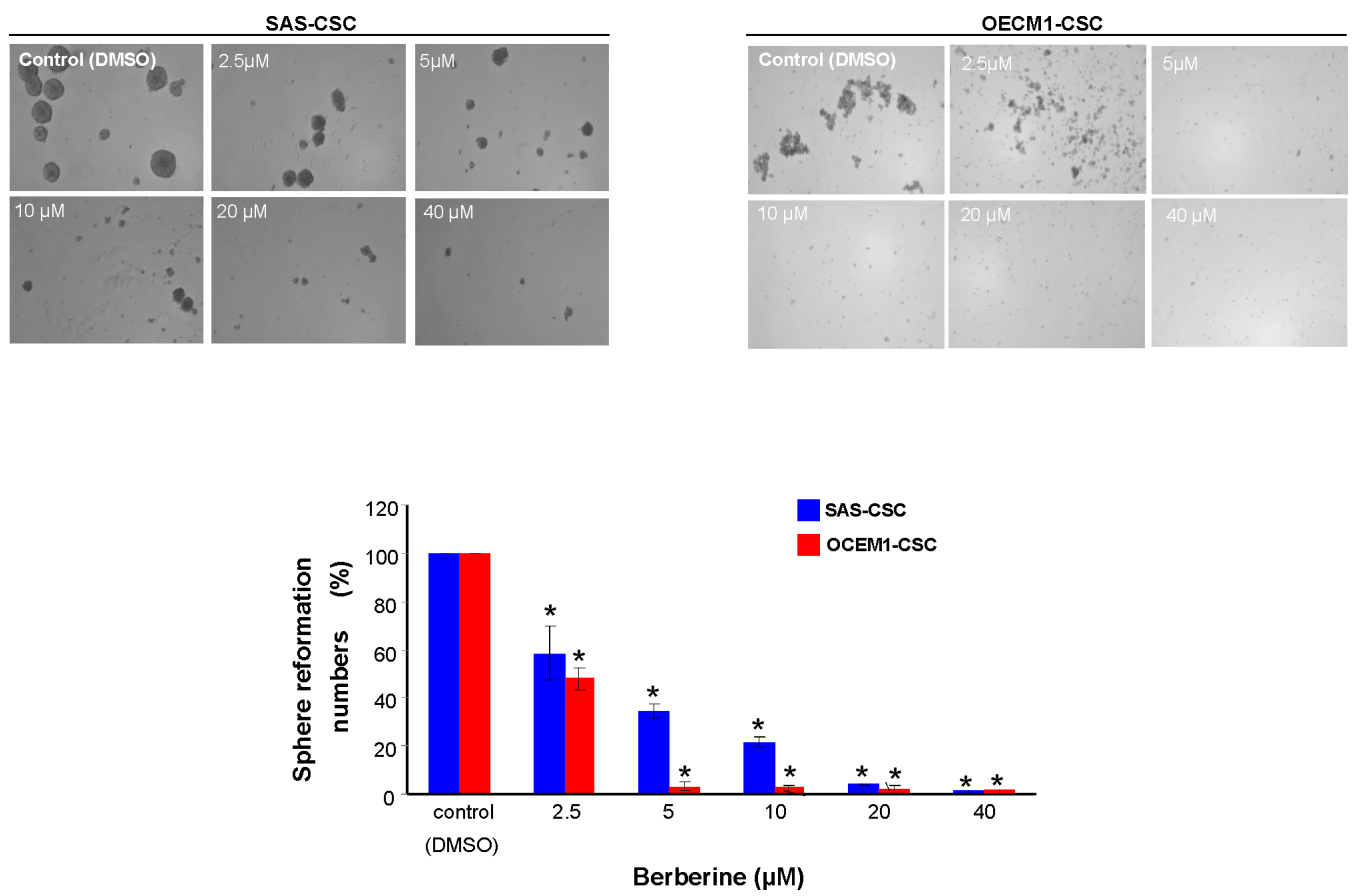

Figure 2: Inhibition of self-renewal property in OCSC after berberine administration. Secondary sphere formation ability of berberine-treated cells was examined. The percentage of the sphere formation was suppressed by berberine in both OSCC-CSCs. Values were expressed as mean \pm SD. * $p<.05$ compared to DMSO control. 
A
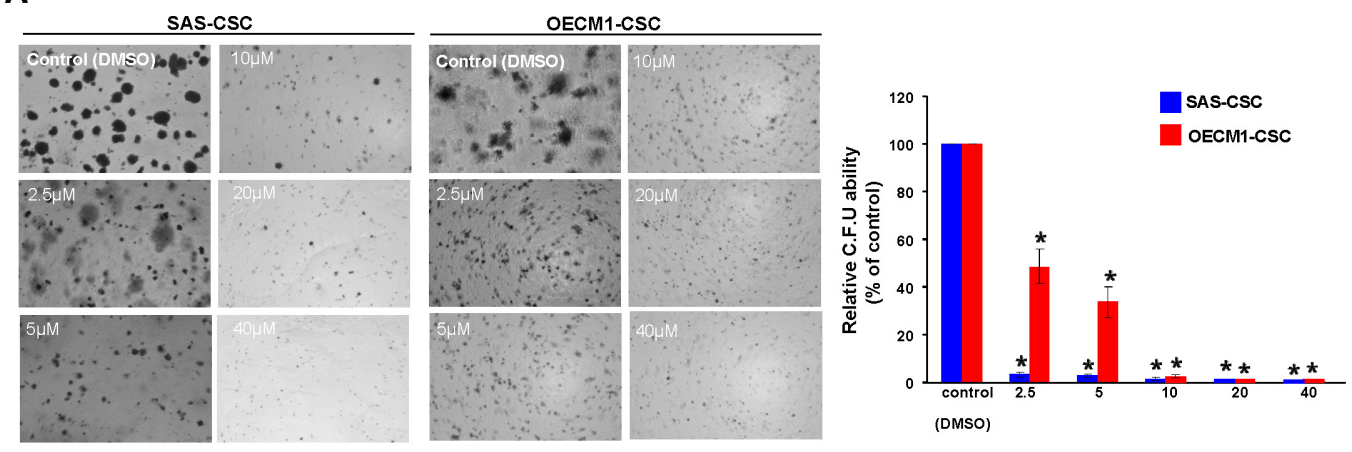

B
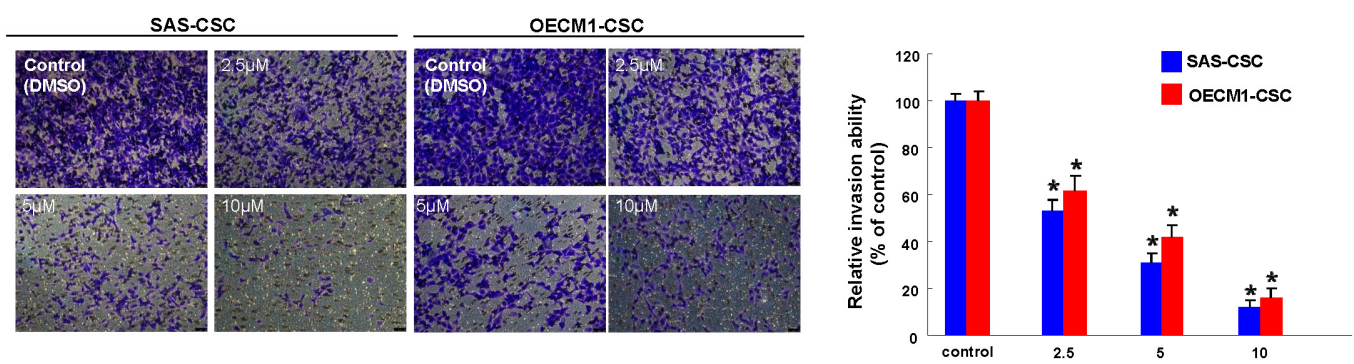

Figure 3: Oncogenicity abilities were hindered by berberine. (A) Colony formation capacity in OSCC-CSCs was reduced by administration of berberine; (B) The invasion potential of OSCC-CSCs was interfered by berberine in a dose-dependent fashion. Values were expressed as mean $\pm \mathrm{SD}$. ${ }^{*} p<.05$ compared to DMSO control.

A

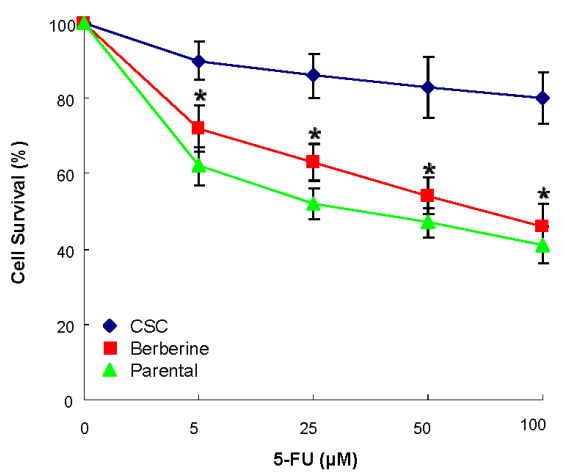

C

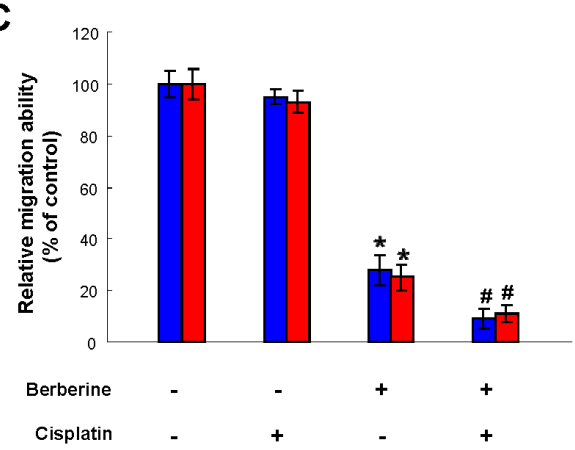

B

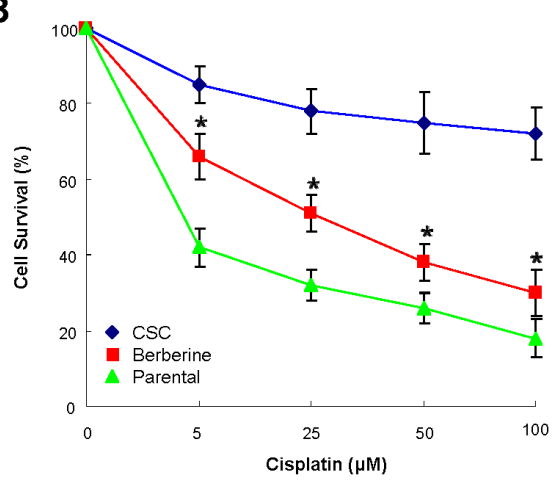

D

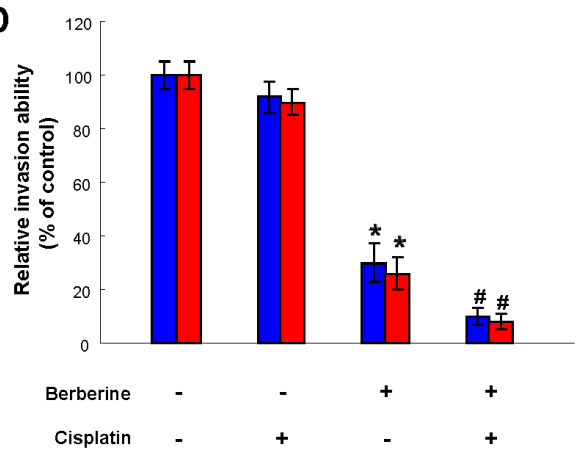

Figure 4: Use of berberine to potentiate chemotherapy. Cell viability data suggested that chemoresistance to 5-FU (A) cisplatin (B) or were more obvious in OSCC-CSCs compared to parental OSCC cells, while chemosensitivity in OSCC-CSCs was enhanced by berberine treatment. The relative migration (C) and invasion (D) capacities of OSCC-CSCs were improved after berberine alone treatment or in conjunction with cisplatin. Values were expressed as mean \pm SD. $* p<.05$ compared to no treatment control. 
were in accord with the volume of the excised tumors (Figure 5A and 5B), and both of them displayed a dose dependent reduction of tumor. We demonstrated that the tumor growth was significantly delayed after treatment of berberine (Figure 5C) without causing body weight loss (Figure 5D).

\section{The anti-CSC effect of berberine is via down- regulation of $\mathrm{miR}-21$}

miRNAs have recently been linked to regulate cancer stemness in OSCC. A significant increase in oncogenic miR-21 expression was in OSCC-CSCs relative to parental OSCC cells (Figure 6A). The expression of miR-21 in two OSCC-CSCs was reduced after berberine in a dose-dependent fashion (Figure 6B). We showed that inhibition of endogenous miR-21 using sponges to create loss-of-function phenotype led to reduced self-renewal (Figure 6C), migration (Figure 6D) and invasion (Figure 6E) capabilities. Additionally, the ALDH1 activity was suppressed in both OSCC-CSCs after knockdown of miR-

A
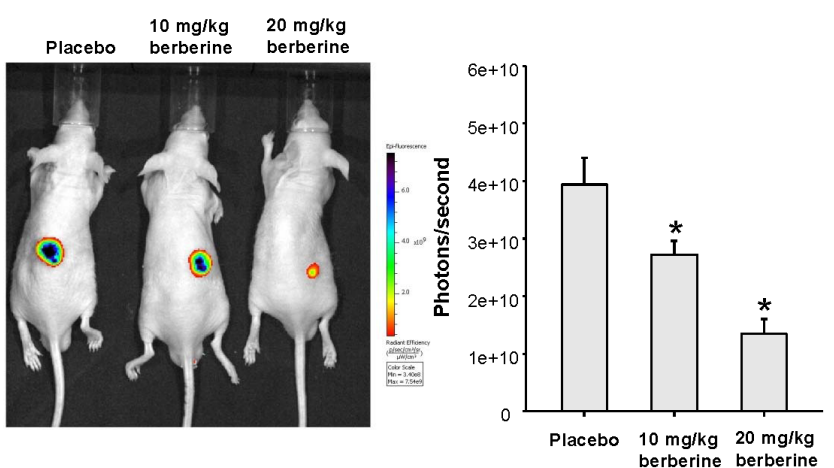

C

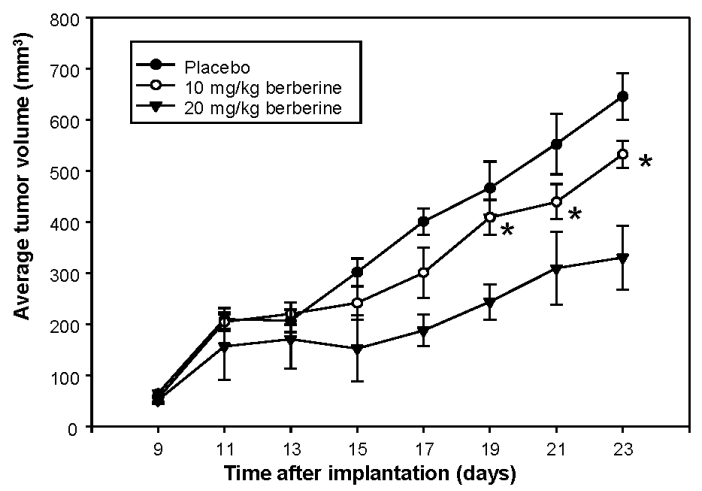

21 (Figure 6F). And these data indicated that the repressed hallmarks of CSCs may be associated with the reduced miR-21 following berberine treatment.

\section{DISCUSSION}

Drug resistance and cancer recurrence remain as major causes of death in patients with OSCC [2]. Among various factors regulating cancer aggressiveness, miR-21 has been recently indicated as an important contributing factor. It has not only been identified as one of the most upregulated miRNAs in OSCC [26] but also shown to confer resistance to chemotherapy in various cancers [2730]. Several studies have suggested that overexpression of miR-21 dramatically reduced the therapeutic efficacy of chemotherapy via downregulating the expression of human mutS homolog $2[29,37]$ or PTEN/ Akt pathway $[28,30]$, whereas inhibition of miR-21 reversed this effect and therefore reduced oncogenicity $[30,37]$. In accordance with these findings, we demonstrated that downregulation of miR-21 by berberine reduced the expression of CSC

B
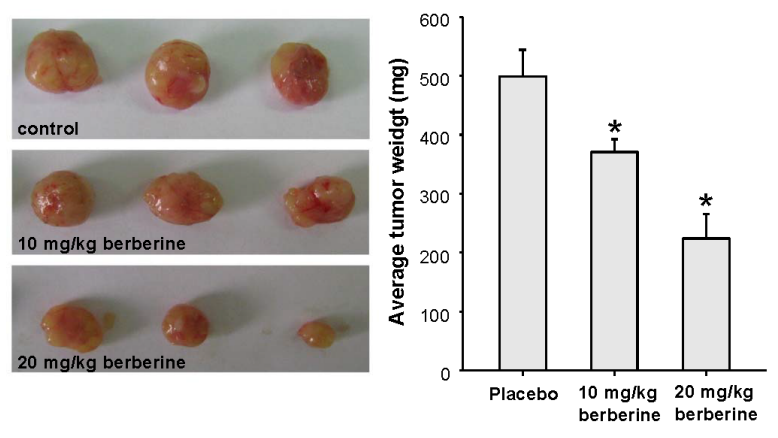

D

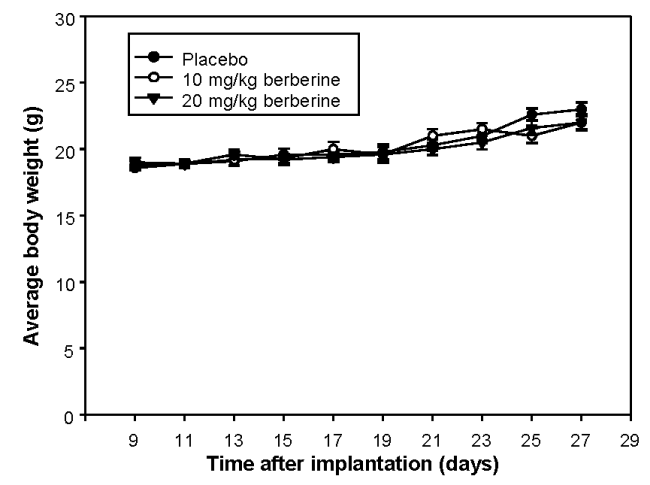

Figure 5: The anti-tumor effect of berberine in vivo. The bioluminescent signal (A) and the excised tumor (B) both showed that tumor size was reduced by berberine treatment; (C) Data from IVIS Spectrum imager indicated that tumor growth was significantly delayed after delivery of berberine in mice bearing OSCC-CSCs xenografts; (D) Body weight of the mice was not affected by administration of berberine. Values were expressed as mean $\pm \mathrm{SD} . * p<.05$ compared to placebo group. 
marker and inhibited the self-renewal, migration and invasion capabilities of OSCC-CSCs (Figure 6).

As a matter of fact, berberine has been proven to inhibit the growth of various cancers through suppression of EMT [14, 15], induction of apoptosis [11, 18-20, 38$43]$ and autophagy $[16,17]$, and cell cycle arrest $[11,41$, $42,44]$ as well as to reduce the metastatic potential via inhibition of COX-2/ $\mathrm{PGE}_{2}$ [12] or AMPK/ ERK pathways [13]. Berberine was also reported to diminish the CSCs [21], which play a crucial role in relapse of cancer and metastasis. In the current study, we further showed the direct inhibitory effect of berberine on OSCC-CSCs via targeting miR-21, resulting in attenuated tumor growth in vivo.

Most importantly, we demonstrated that berberine potentiated chemotherapy by downregulation of miR-21. It has been suggested that miR-21 confers chemoresistance in cancer cells by regulating the expression of phosphatase and tensin homolog (PTEN) and programmed cell death 4 (PD4D4) [27, 28, 30], and berberine sensitizes cancer cells through PTEN/ Akt signaling pathway [22]. Moreover, it was reported that berberine improves the therapeutic efficiency of cisplatin through miR-21/PDCD4 axis [45]. As such, it is possible that PTEN and PD4D4 are involved in the chemosensitizing effect. In addition, it was reported that berberine suppresses multiple myeloma cell growth by reducing miR-21 through IL6/Stat3 regulation [31]. Further investigation is needed to unravel the detailed mechanism underlying the association between berberine and miR-2 1 in chemosensitizing effect of OSCC.

In conclusion, we showed the anti-CSC effect of berberine on oral cancer via targeting miR-21, therefore leading to reduction of self-renewal and metastatic properties in vitro and attenuation of tumor growth in vivo. Our findings provided the evidence for using the natural berberine as an adjunctive therapy to traditional chemotherapeutics.

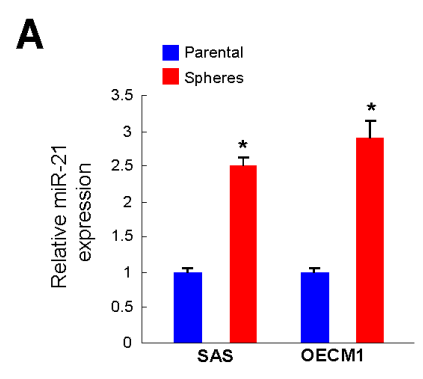

B

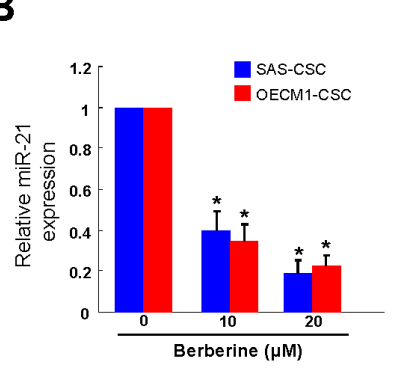

C
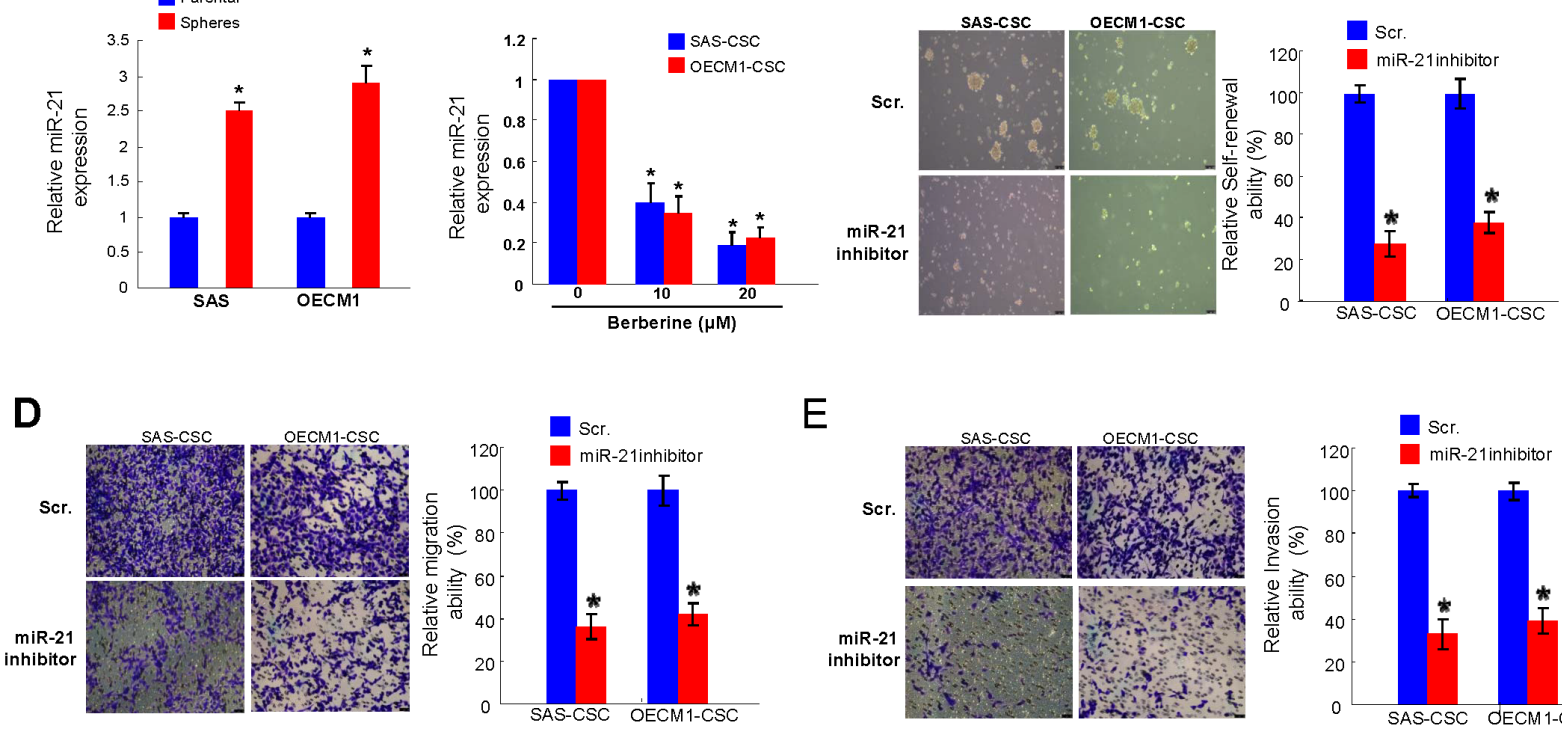

$E$
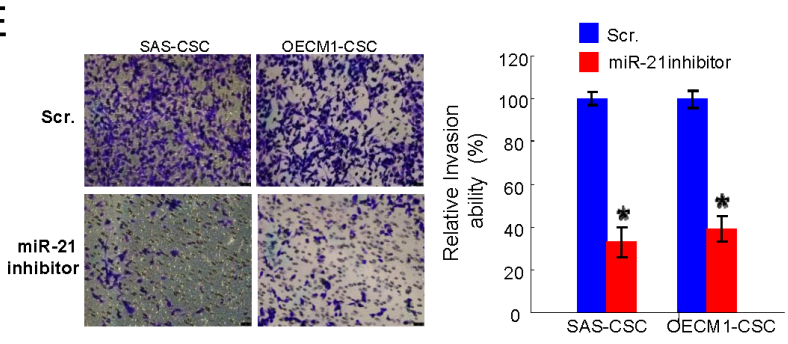

F
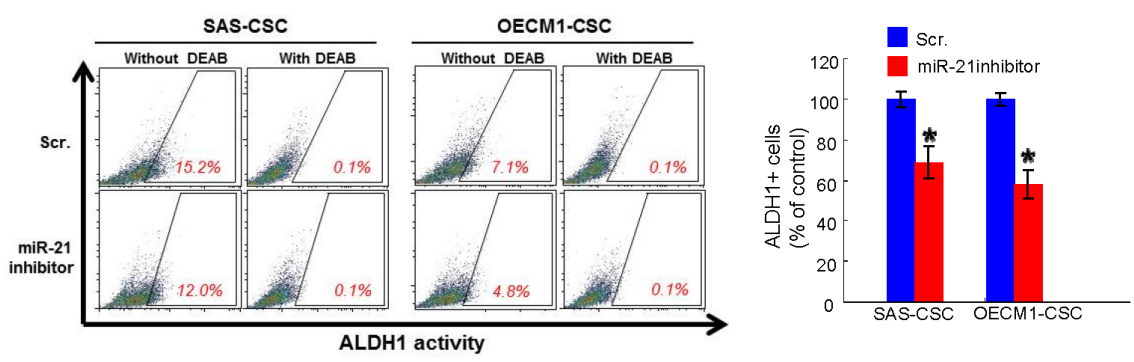

Figure 6: Berberine-mediated anti-tumor response is via down-regulation of miR-21. (A) Relative of miR-21 expression in OSCC-CSCs and OSCC cell lines was examined by miRNAs real-time RT-PCR analysis. (B) The expression of miR-21 was reduced after berberine in both OSCC-CSCs; Inhibition of miR-21 using sponges abrogated the self-renewal (C), migration (D) and invasion (E) abilities of OSCC-CSCs; (F) The ALDH1 enzymatic activity was reduced by miR-21 inhibitor. Values were expressed as mean \pm SD. ${ }^{*} p$ $<.05$ compared to control group. 


\section{MATERIALS AND METHODS}

\section{Reagent and cell culture}

Berberine was purchased from Sigma-Aldrich Chemical Co. (St. Louis, MO, USA) Berberine was further diluted in culture medium to the appropriate final concentrations prior to use. The CSCs derived from OSCC cell lines SAS and OECM-1 as well as primary normal human gingival epithelioid cell line (SG) were cultivated as previously described [34].

\section{Cell viability assay}

Cytotoxicity of berberine was determined by MTT (Sigma, St. Louis, MO) assay. Cells were seeded in 24-well plates $\left(1 \times 10^{4}\right.$ cells/ well $)$ in the presence of various concentration of berberine or vehicle at $37^{\circ} \mathrm{C}$ for 24 hours followed by incubation with MTT reagent. After removing the supernatant, blue formazan crystals of viable cells were dissolved in DMSO and evaluated spectrophotometrically at $570 \mathrm{~nm}$. DMSO-treated group was set as $100 \%$, and data were presented as percentage of DMSO control.

\section{Aldefluor $^{\mathrm{TM}}$ assay}

ALDH1 enzymatic activity was detected using the Aldefluor $^{\mathrm{TM}}$ kit (Stem Cell Technologies Inc., Vancouver, Canada) according to the manufacturer's instructions. Cells stained with a specific ALDH inhibitor, 4-diethylaminobenzaldehyde (DEAB), served as negative control. Fluorescence emission from 10,000 cells was assessed with FACSCalibur (Becton Dickinson, Mountain View, CA, USA) using CellQuest software

\section{Secondary sphere formation assay}

Cells were dissociated and cultured in the modified DMEM/F-12 supplemented with N2 (R\&D Minneapolis, $\mathrm{MN}, \mathrm{USA}$ ), $10 \mathrm{ng} / \mathrm{mL}$ epidermal growth factor (Invitrogen, Carlsbad, CA, USA), $10 \mathrm{ng} / \mathrm{mL}$ basic fibroblast growth factor (Invitrogen) and penicillin/streptomycin at $10^{4}$ live cells/low-attachment six-well plate (Corning Inc., Corning, NY, USA) along with various concentration of berberine. Cell density/ 10,000 cells were calculated and shown as percentage of control group.

\section{Soft agarose assay}

Each well of a six-well culture dish was coated with $1 \mathrm{ml}$ of bottom agar (Sigma-Aldrich) mixture (DMEM/F-12, 15\% (v/v) FBS, $0.525 \%$ (w/v) agar). After the bottom layer was solidified, $1 \mathrm{ml}$ of top agar-medium mixture (DMEM/F-12, 15\% (v/v) FBS, 0.3\% (w/v) agar) containing $4 \times 10^{4}$ cells was added, and the dishes were incubated at $37^{\circ} \mathrm{C}$ for 2 weeks. Plates were stained with $0.01 \%$ crystal violet, and then the colonies were counted.

\section{Cell invasion and migration assays}

The 24-well plate Transwell system with a polycarbonate filter membrane of $8-\mu \mathrm{m}$ pore size (Corning, United Kingdom) was used to evaluate the migration and invasion abilities of cells. The membrane was coated with Matrigel (BD Pharmingen, NJ, USA) for invasion. The cell suspensions were seeded to the upper chamber of the Transwell insert within serum-free medium at the cell density of $5 \times 10^{4}$ and $1 \times 10^{5}$ for migration and invasion assays, respectively. The lower chamber was filled with media supplemented with $10 \%$ serum and various concentration of berberine. After 24 hours of incubation, the filter membrane was stained with crystal violet. The migrated and invasion cells were counted from five different visual areas of 100-fold magnification under an inverted microscope.

\section{Measurement of tumor growth in vivo}

All procedures involving animals were conducted in accordance with the institutional animal welfare guidelines of the Chung Shan Medical University. 5-6 weeks old immuno-deficient nude mice (BALB/c nu/nu mice) were used for the xenograft model. OCSC $\left(1 \times 10^{4}\right.$ cells $/ 0.2 \mathrm{~mL} /$ mouse) were injected subcutaneously into the right axilla and the day of cell implantation was designated as day 0 . Mice were randomly divided into two groups and fed with either placebosaline (control) or berberine (10 and 20 $\mathrm{mg} / \mathrm{kg}$ per day) by oral gavage. Tumor size measurement was performed using an IVIS50 animal imaging system (Xenogen Corp.). The volume was calculated (according to the following formula: [length $\times$ width $\left.^{2}\right] / 2$ ), and then analyzed by Image-Pro Plus software. After 23 days, animals were euthanized followed by tissue excision for phosphor-Stat3 analysis.

\section{miR-21 down-regualtion}

miR-21 inhibitor, and scramble (Scr) control were purchased from Applied Biosystems (Foster City, CA, USA). LipofectamineTM 3000 transfection reagent (Invitrogen, Thermo Fisher Scientific Inc., Carlsbad, CA, USA) according to the manufacturer's protocol was used as the transfection reagent.

\section{Statistical analysis}

SPSS software (version 13.0; SPSS, Inc., Chicago, IL, USA) was used for statistical analysis. The presented results are representative of three independent experiments with similar results. Statistical differences were evaluated with the Student $t$ test, and $p<0.05$ was considered significant. 


\section{ACKNOWLEDGMENTS}

This study was supported by grant from Chung Shan Medical University Hospital (CSH-2016-C-009) and Chung Shan Medical University and Chi Mei Hospital (CSMU-CMMC-104-04; CMCSMU10406) in Taiwan.

\section{CONFLICTS OF INTEREST}

The authors have declared no conflicts of interest.

\section{REFERENCES}

1. Chen YJ, Chang JT, Liao CT, Wang HM, Yen TC, Chiu $\mathrm{CC}, \mathrm{Lu} \mathrm{YC}$, Li HF, Cheng AJ. Head and neck cancer in the betel quid chewing area: recent advances in molecular carcinogenesis. Cancer Sci. 2008; 99:1507-14.

2. Hasegawa T, Shibuya Y, Takeda D, Iwata E, Saito I, Kakei Y, Sakakibara A, Akashi M, Minamikawa T, Komori T. Prognosis of oral squamous cell carcinoma patients with level IV/V metastasis: An observational study. J Craniomaxillofac Surg. 2017; 45:145-49.

3. Gibson MK, Forastiere AA. Reassessment of the role of induction chemotherapy for head and neck cancer. Lancet Oncol. 2006; 7:565-74.

4. Simple M, Suresh A, Das D, Kuriakose MA. Cancer stem cells and field cancerization of oral squamous cell carcinoma. Oral Oncol. 2015; 51:643-51.

5. Hwang BY, Roberts SK, Chadwick LR, Wu CD, Kinghorn AD. Antimicrobial constituents from goldenseal (the Rhizomes of Hydrastis canadensis) against selected oral pathogens. Planta Med. 2003; 69:623-27.

6. Hu JP, Takahashi N, Yamada T. Coptidis rhizoma inhibits growth and proteases of oral bacteria. Oral Dis. 2000; 6:297-302.

7. Kuo CL, Chi CW, Liu TY. The anti-inflammatory potential of berberine in vitro and in vivo. Cancer Lett. 2004; 203:127-37.

8. Tomosaka H, Chin YW, Salim AA, Keller WJ, Chai H, Kinghorn AD. Antioxidant and cytoprotective compounds from Berberis vulgaris (barberry). Phytother Res. 2008; 22:979-81.

9. Abd El-Wahab AE, Ghareeb DA, Sarhan EE, Abu-Serie MM, El Demellawy MA. in vitro biological assessment of Berberis vulgaris and its active constituent, berberine: antioxidants, anti-acetylcholinesterase, anti-diabetic and anticancer effects. BMC Complement Altern Med. 2013; $13: 218$.

10. Tsang CM, Lau EP, Di K, Cheung PY, Hau PM, Ching YP, Wong YC, Cheung AL, Wan TS, Tong Y, Tsao SW, Feng Y. Berberine inhibits Rho GTPases and cell migration at low doses but induces G2 arrest and apoptosis at high doses in human cancer cells. Int J Mol Med. 2009; 24:131-8.
11. Mantena SK, Sharma SD, Katiyar SK. Berberine, a natural product, induces G1-phase cell cycle arrest and caspase3 -dependent apoptosis in human prostate carcinoma cells. Mol Cancer Ther. 2006; 5:296-308.

12. Singh T, Vaid M, Katiyar N, Sharma S, Katiyar SK. Berberine, an isoquinoline alkaloid, inhibits melanoma cancer cell migration by reducing the expressions of cyclooxygenase-2, prostaglandin $\mathrm{E}_{2}$ and prostaglandin $\mathrm{E}_{2}$ receptors. Carcinogenesis. 2011; 32:86-92.

13. Kim HS, Kim MJ, Kim EJ, Yang Y, Lee MS, Lim JS. Berberine-induced AMPK activation inhibits the metastatic potential of melanoma cells via reduction of ERK activity and COX-2 protein expression. Biochem Pharmacol. 2012; 83:385-94.

14. Kou Y, Li L, Li H, Tan Y, Li B, Wang K, Du B. Berberine suppressed epithelial mesenchymal transition through cross-talk regulation of PI3K/AKT and RAR $\alpha /$ RAR $\beta$ in melanoma cells. Biochem Biophys Res Commun. 2016; 479:290-6.

15. Qi HW, Xin LY, Xu X, Ji XX, Fan LH. Epithelial-tomesenchymal transition markers to predict response of Berberine in suppressing lung cancer invasion and metastasis. J Transl Med. 2014; 12:22.

16. La X, Zhang L, Li Z, Yang P, Wang Y. Berberine-induced autophagic cell death by elevating GRP78 levels in cancer cells. Oncotarget. 2017; 8:20909-24. https://doi. org/10.18632/oncotarget.14959.

17. Wang J, Qi Q, Feng Z, Zhang X, Huang B, Chen A, Prestegarden L, Li X, Wang J. Berberine induces autophagy in glioblastoma by targeting the AMPK/mTOR/ULK1pathway. Oncotarget. 2016; 7:66944-58. https://doi. org/10.18632/oncotarget.11396.

18. Wang J, Yang S, Cai X, Dong J, Chen Z, Wang R, Zhang S, Cao H, Lu D, Jin T, Nie Y, Hao J, Fan D. Berberine inhibits EGFR signaling and enhances the antitumor effects of EGFR inhibitors in gastric cancer. Oncotarget. 2016; 7:76076-76086. https://doi.org/10.18632/oncotarget.12589.

19. Lin CC, Yang JS, Chen JT, Fan S, Yu FS, Yang JL, Lu CC, Kao MC, Huang AC, Lu HF, Chung JG. Berberine induces apoptosis in human HSC-3 oral cancer cells via simultaneous activation of the death receptor-mediated and mitochondrial pathway. Anticancer Res. 2007; 27:3371-8.

20. Kim JS, Oh D, Yim MJ, Park JJ, Kang KR, Cho IA, Moon SM, Oh JS, You JS, Kim CS, Kim DK, Lee SY, Lee GJ, et al. Berberine induces FasL-related apoptosis through p38 activation in KB human oral cancer cells. Oncol Rep. 2015; 33:1775-82.

21. Park SH, Sung JH, Chung N. Berberine diminishes side population and down-regulates stem cell-associated genes in the pancreatic cancer cell lines PANC-1 and MIA PaCa2. Mol Cell Biochem. 2014; 394:209-15.

22. Chen Q, Qin R, Fang Y, Li H. Berberine Sensitizes Human Ovarian Cancer Cells to Cisplatin Through miR-93/PTEN/ 
Akt Signaling Pathway. Cell Physiol Biochem. 2015; 36:956-65.

23. Yu SL, Chen HY, Chang GC, Chen CY, Chen HW, Singh $\mathrm{S}$, Cheng CL, Yu CJ, Lee YC, Chen HS, Su TJ, Chiang CC, $\mathrm{Li} \mathrm{HN}$, et al. MicroRNA signature predicts survival and relapse in lung cancer. Cancer Cell. 2008; 13:48-57. http:// dx.doi.org/10.1016/j.ccr.2007.12.008.

24. Seike M, Goto A, Okano T, Bowman ED, Schetter AJ, Horikawa I, Mathe EA, Jen J, Yang P, Sugimura H, Gemma A, Kudoh S, Croce CM, et al. MiR-21 is an EGFR-regulated anti-apoptotic factor in lung cancer in never-smokers. Proc Natl Acad Sci U S A. 2009; 106:12085-90. https://doi. org/10.1073/pnas.0905234106.

25. Iorio MV, Casalini P, Tagliabue E, Menard S, Croce CM. MicroRNA profiling as a tool to understand prognosis, therapy response and resistance in breast cancer. Eur J Cancer. 2008; 44:2753-9. https://doi.org/10.1016/j. ejca.2008.09.037.

26. Gombos K, Horváth R, Szele E, Juhász K, Gocze K, Somlai K, Pajkos G, Ember I, Olasz L. miRNA expression profiles of oral squamous cell carcinomas. Anticancer Res. 2013; 33:1511-7.

27. Tomimaru Y, Eguchi H, Nagano H, Wada H, Tomokuni A, Kobayashi S, Marubashi S, Takeda Y, Tanemura M, Umeshita K, Doki Y, Mori M. MicroRNA-21 induces resistance to the anti-tumour effect of interferon- $\alpha / 5$ fluorouracil in hepatocellular carcinoma cells. Br J Cancer. 2010; 103:1617-26.

28. Chen Y, Tsai YH, Fang Y, Tseng SH. Micro-RNA-21 regulates the sensitivity to cisplatin in human neuroblastoma cells. J Pediatr Surg. 2012; 47:1797-805.

29. Valeri N, Gasparini P, Braconi C, Paone A, Lovat F, Fabbri M, Sumani KM, Alder H, Amadori D, Patel T, Nuovo GJ, Fishel R, Croce CM. MicroRNA-21 induces resistance to 5-fluorouracil by down-regulating human DNA MutS homolog 2 (hMSH2). Proc Natl Acad Sci U S A. 2010; 107:21098-103.

30. Yang SM, Huang C, Li XF, Yu MZ, He Y, Li J. miR-21 confers cisplatin resistance in gastric cancer cells by regulating PTEN. Toxicology. 2013; 306:162-8.

31. Luo X, Gu J, Zhu R, Feng M, Zhu X, Li Y, Fei J. Integrative analysis of differential miRNA and functional study of miR21 by seed-targeting inhibition in multiple myeloma cells in response to berberine. BMC Syst Biol. 2014; 8:82.

32. Clay MR, Tabor M, Owen JH, Carey TE, Bradford CR, Wolf GT, Wicha MS, Prince ME. Single-marker identification of head and neck squamous cell carcinoma cancer stem cells with aldehyde dehydrogenase. Head Neck. 2010; 32:1195-201.

33. Ota N, Ohno J, Seno K, Taniguchi K, Ozeki S. in vitro and in vivo expression of aldehyde dehydrogenase 1 in oral squamous cell carcinoma. Int J Oncol. 2014; 44:435-42.
34. Yu CC, Tsai LL, Wang ML, Yu CH, Lo WL, Chang YC, Chiou GY, Chou MY, Chiou SH. miR145 targets the SOX9/ ADAM17 axis to inhibit tumor-initiating cells and IL-6mediated paracrine effects in head and neck cancer. Cancer Res. 2013; 73:3425-40.

35. Leemans CR, Braakhuis BJ, Brakenhoff RH. The molecular biology of head and neck cancer. Nat Rev Cancer. 2011; 11:9-22.

36. Dean M, Fojo T, Bates S. Tumour stem cells and drug resistance. Nat Rev Cancer. 2005; 5:275-84. https://doi. org/10.1038/nrc1590.

37. Deng J, Lei W, Fu JC, Zhang L, Li JH, Xiong JP. Targeting miR-21 enhances the sensitivity of human colon cancer HT-29 cells to chemoradiotherapy in vitro. Biochem Biophys Res Commun. 2014; 443:789-95.

38. Choi MS, Oh JH, Kim SM, Jung HY, Yoo HS, Lee YM, Moon DC, Han SB, Hong JT. Berberine inhibits p53dependent cell growth through induction of apoptosis of prostate cancer cells. Int J Oncol. 2009; 34:1221-30.

39. Choi MS, Yuk DY, Oh JH, Jung HY, Han SB, Moon DC, Hong JT. Berberine inhibits human neuroblastoma cell growth through induction of p53-dependent apoptosis. Anticancer Res. 2008; 28:3777-84.

40. Ho YT, Lu CC, Yang JS, Chiang JH, Li TC, Ip SW, Hsia TC, Liao CL, Lin JG, Wood WG, Chung JG. Berberine induced apoptosis via promoting the expression of caspase- $8,-9$ and -3 , apoptosis-inducing factor and endonuclease G in SCC-4 human tongue squamous carcinoma cancer cells. Anticancer Res. 2009; 29:4063-70.

41. Lin JP, Yang JS, Lee JH, Hsieh WT, Chung JG. Berberine induces cell cycle arrest and apoptosis in human gastric carcinoma SNU-5 cell line. World J Gastroenterol. 2006; 12:21-8.

42. Liu Z, Liu Q, Xu B, Wu J, Guo C, Zhu F, Yang Q, Gao G, Gong Y, Shao C. Berberine induces p53-dependent cell cycle arrest and apoptosis of human osteosarcoma cells by inflicting DNA damage. Mutat Res. 2009; 662:75-83.

43. Patil JB, Kim J, Jayaprakasha GK. Berberine induces apoptosis in breast cancer cells (MCF-7) through mitochondrial-dependent pathway. Eur J Pharmacol. 2010; 645:70-8.

44. Eo SH, Kim JH, Kim SJ. Induction of $\mathrm{G}_{2} / \mathrm{M}$ Arrest by Berberine via Activation of PI3K/Akt and p38 in Human Chondrosarcoma Cell Line. Oncol Res. 2014; 22:147-57.

45. Liu S, Fang Y, Shen H, Xu W, Li H. Berberine sensitizes ovarian cancer cells to cisplatin through miR-21/PDCD4 axis. Acta Biochim Biophys Sin (Shanghai). 2013; 45:756-62. 